\title{
Interleukin 7 Is Produced by Human Intestinal Epithelial Cells and Regulates the Proliferation of Intestinal Mucosal Lymphocytes
}

\author{
Mamoru Watanabe, * Yoshitaka Ueno, * Tomoharu Yajima, " Yasushi Iwao, " Masaharu Tsuchiya, " Hiromichi Ishikawa, \\ Sadakazu Aiso, ${ }^{5}$ Toshifumi Hibi," and Hiromasa Ishii* \\ Departments of * Internal Medicine, ${ }^{\ddagger}$ Microbiology, and ${ }^{\S}$ Anatomy, School of Medicine, Keio University; and ${ }^{\| K e i o}$ Cancer Center, \\ Tokyo 160, Japan
}

\begin{abstract}
The interaction of mucosal lymphocytes and intestinal epithelial cells is thought to be important in regulating immune response in the intestinal mucosa, but conclusive evidence is limited. Here we demonstrate the expression of $\mathrm{IL-7}$ mRNA in human intestinal mucosa by combined reverse transcription PCR and Southern blot hybridization. Immunohistochemistry and in situ hybridization confirm the presence of IL-7 in intestinal epithelial cells, especially in epithelial goblet cells. Moreover, $\mathbf{L}-7$ receptor expression in mucosal lymphocytes is demonstrated by immunohistochemistry and in situ hybridization, as well as by Southern blot and flow cytometric analysis of freshly isolated lamina propria lymphocytes. In contrast, $\mathrm{IL-7}$ receptor could not be detected in the cell surface of freshly isolated PBLs. The functional activity of $\mathrm{L}-7$ receptor is demonstrated by the utility of recombinant $\mathrm{L}-7$ to stimulate the growth of lamina propria lymphocytes, and conversely inhibit CD3-dependent proliferation of these cells. In contrast, IL-7 caused no significant increase in DNA synthesis and cell numbers when added to PBLs. These findings suggest that human intestinal epithelial cells and epithelial goblet cells produce IL-7, and locally produced IL-7 may serve as a potent regulatory factor for intestinal mucosal lymphocytes. (J. Clin. Invest. 1995. 95:2945-2953.) Key words: interleukin 7 receptor $\bullet$ mucosal immunity • goblet cell • lamina propria lymphocyte $\bullet$ intestinal mucosa
\end{abstract}

\section{Introduction}

The intestinal mucosa is continuously exposed to a variety of foreign antigens. Intestinal mucosal lymphocytes, the intraepi-

Address correspondence to Mamoru Watanabe, Department of Internal Medicine, School of Medicine, Keio University, 35 Shinanomachi, Shinjuku-ku, Tokyo 160, Japan. Phone and FAX:81-3-3357-6156.

Received for publication 20 May 1994 and in revised form 21 February 1995.

1. Abbreviations used in this paper: dig, digoxigenin; G3PDH, glyceraldehyde 3-phosphate dehydrogenase; IEL, intraepithelial lymphocyte; LPL, lamina propria lymphocyte; rIL, recombinant IL; TcR, T cell receptor.

J. Clin. Invest.

(C) The American Society for Clinical Investigation, Inc.

0021-9738/95/06/2945/09 \$2.00

Volume 95, June 1995, 2945-2953 thelial lymphocytes (IELs), ${ }^{1}$ and lamina propria lymphocytes (LPLs), located adjacent to the intestinal lumen and mucosal barrier, may initiate local immune responses to those exogenous antigens (1-3), monitor intestinal enterocytes, and respond to nonpolymorphic molecules such as CD1d expressed on the surface of epithelial cells $(4,5)$. These mucosal lymphocytes may serve a critical role in the mucosal immune system by providing immune surveillance of epithelial cells (6). However, little is known about the precise mechanism by which functional differentiation and proliferation of these cells occurs in the intestinal mucosa. Although recent studies have shown that cytokines released from mucosal mononuclear cells may affect intestinal epithelial cell differentiation $(7,8)$, the signals originating from epithelial cells that may regulate mucosal lymphocytes are as yet undefined.

IL-7 is a stromal cell-derived pleiotropic cytokine with lymphoid precursor cell growth-promoting activity (9-14). Recent studies have demonstrated IL-7 mRNA expression in bone marrow stromal cells, thymus, spleen, liver, kidney, and keratinocytes $(15,16)$. We sought to investigate the role of IL7 in the growth and differentiation of the intestinal mucosal lymphocytes. We have done this by assessing the expression of IL-7 and IL-7 receptor $(17,18)$ in the human intestinal mucosa. Here we report IL-7 mRNA expression and IL-7 protein production in the colonic epithelial cells and epithelial goblet cells. These results, in concert with the findings that IL-7 receptors are expressed by mucosal lymphocytes, suggest that IL-7 produced in the intestinal epithelium may serve as a regulatory factor for the intestinal mucosal lymphocytes.

\section{Methods}

Normal human intestinal mucosa from biopsied tissues. Normal intestinal mucosa was obtained from the biopsied specimens of colonic tissues from normal appearing rectal and sigmoid colonic mucosa of seven healthy unrelated adult males undergoing screening sigmoidoscopy. Small intestinal biopsies from the third portion of the duodenum and stomach biopsies were obtained in five individuals with a normal upper intestinal endoscopy. Mucosal biopsies from the colon, small intestine, and stomach were $2-3 \mathrm{~mm}$ in size. Histopathological examination revealed no malignancy and inflammation in the gastrointestinal tissues we used. The mucosa was prepared immediately after stripping from the underlying submucosa by blunt dissection. PBLs, obtained at the time of intestinal biopsy, were separated from whole blood. All experiments were approved by the Keio University Hospital Committee on Human Subjects, Tokyo, Japan.

Cell lines. We used a human liver adenocarcinoma cell line, SKHEP-1 (American Type Culture Collection [ATCC], Rockville, MD) as a positive control cell line for mRNA expression of $\mathrm{IL}-7$, because it was used to clone the cDNA for human IL-7 (10). SV40-transformed 
human lung cell line, WI-26 VA4 (ATCC) was used as a positive control cell line for IL-7 receptor mRNA, because it was shown to express high levels of human IL-7 receptor and used to clone the cDNA for human IL-7 receptor (18). Two human Burkitt's lymphoma cell lines, Daudi (as a positive control) and Raji (as a negative control) (ATCC), were used for detecting of IL-7 receptor cell surface expression by flow cytometric analysis. Daudi was shown to express IL-7 receptor on the cell surface but Raji did not (19). The human colonic epithelial cell lines HT29 and Caco-2 were obtained from ATCC. The HT29-18-N2 subclone exhibits intestinal epithelial goblet cell phenotype in the subconfluent or postconfluent state, as assessed by morphological differentiation and expression of mucin glycoprotein (20). The Caco2 cell line undergoes enterocytic differentiation, but does not exhibit goblet cell phenotype. Human hepatocyte cell line, Chang, was kindly provided by $\mathrm{K}$. Toda, Kitasato Institute Hospital, Tokyo, Japan. These cell lines were tested for the expression of IL-7 receptor mRNA.

$P C R$ and Southern blot hybridization for $I L-7$ and IL-7 receptor mRNA. Cytoplasmic RNA was prepared from human intestinal mucosa and cell lines using the RNAzol (Biotecx Laboratories, Inc., Houston, TX). First-strand cDNA was synthesized from $2 \mu \mathrm{g}$ of total RNA with $1 \mu \mathrm{g}$ oligo (dT) primer and $400 \mathrm{U} / \mu \mathrm{l}$ Moloney murine leukemia virus reverse transcriptase (Perkin-Elmer Cetus Instruments, Norwalk, $C T$ ) by using SuperScript Preamplification System (GIBCO BRL, Gaithersburg, MD) in $20 \mu \mathrm{l}$ of the reaction mixture (21). All the PCR primers for human IL-7, IL-7 receptor, and G3PDH (glyceraldehyde 3-phosphate dehydrogenase) (as a house-keeping gene) gene-specific amplification of cDNA in the analysis of mRNA expression by reverse transcriptionPCR were purchased from Clontech Laboratories, Inc. (Palo Alto, CA). The sequences for IL-7 PCR primers were: 5 'primer; 5 '-ATGTTCCATGTTTCTTTTAGGTATATCT-3'; 3 'primer; 5'-TGCATTTCTCAAATGCCCTAATCCG-3'; amplified fragment: 681 bp. Primers for human IL-7 receptor were: 5'primer; 5'-AAAGTGGCTATGCTCAAAATGGAGACTTGG-3'; 3'primer; 5'-TTCCCGATAGATGACACTCAGGTCAAAAGG-3'; amplified fragment: 362 bp. Primers for G3PDH were: 5'primer; 5'-TGAAGGTCGGAGTCAACGGATTTGGT-3'; 3'primer; 5'-CATGTGGGCCATGAGGTCCACCAC-3'; amplified fragment: $983 \mathrm{bp}$, (Mapping Amplimers; Clontech) used as controls. For PCR, $5 \mu \mathrm{l}$ of cDNA was amplified in the presence of 0.5 $\mu \mathrm{M}$ each of the $5^{\prime}$ and $3^{\prime}$ primers, $0.5 \mathrm{U}$ of Thermus aquaticus (Taq) DNA polymerase (Ampli Taq; Perkin-Elmer Cetus Instruments). PCR was performed in a DNA thermal cycler for 30 cycles $\left(94^{\circ} \mathrm{C}\right.$ for $45 \mathrm{~s}$, $60^{\circ} \mathrm{C}$ for $45 \mathrm{~s}$, and $72^{\circ} \mathrm{C}$ for $90 \mathrm{~s}$ ) followed by a $7-\mathrm{min}$ extension at $72^{\circ} \mathrm{C}$. $9 \mu \mathrm{l}$ of the PCR products was subjected to electrophoresis on $1.6 \%$ agarose gels and stained with $0.5 \mu \mathrm{g} / \mathrm{ml}$ ethidium bromide. 100 bp DNA ladder (GIBCO BRL) was used as a marker. The specificity of the PCR products was validated by restriction enzyme digestion and Southern blot hybridization. The amplified IL-7 PCR product ( $681 \mathrm{bp}$ ) was digested by restriction enzyme DraI ( $10 \mathrm{U} / \mu \mathrm{l}, 5^{\prime}$ TTT/AAA 3'; GIBCO BRL) into fragments. The predicted size of three fragments is 248, 230, and $203 \mathrm{bp}$.

For Southern blot, PCR products on the agarose gels were blotted onto nylon membrane (Biodyne; Pall Corp., Glen Cove, NY), and hybridized with IL-7 and IL-7 receptor gene-specific cDNA oligonucleotide probe (Clontech) labeled by digoxigenin (dig)-dUTP using the dig oligonucleotide 3'-end labeling kit (Boehringer Mannheim Biochemicals, Indianapolis, IN). The sequence for human $\mathrm{IL}-7$ probe was: 5' AGTGCAGTTCAACAGTATTGTTGTGCCTTC 3' (738-709) and that for human IL-7 receptor was: 5' GGTGTTGACATCTGGGTCCT $3^{\prime}(220-201)$. Hybridizations were done at $42^{\circ} \mathrm{C}$ for $18 \mathrm{~h}$ in a solution containing $50 \%$ formamide, $5 \times \mathrm{SSC}, 0.02 \% \mathrm{SDS}, 0.1 \% \mathrm{~N}$-lauroyl sarcosine and heat-denatured dig-11-dUTP probe at $10 \mathrm{ng} / \mathrm{ml}$. Blots were washed at a final stringency of $2 \times \mathrm{SSC}$ at $68^{\circ} \mathrm{C}$ and processed for detection of digoxigenin-labeled oligonucleotide probes by ELISA (anti-digoxigenin antibody linked to alkaline phosphatase) using the dig nucleic acid luminescent kit (Boehringer Mannheim Biochemicals), according to the manufacturer's instructions. Subsequently, the membrane was equilibrated and then placed in a dark box containing lumino- gen purified protein derivative. The membrane was incubated for 20 min at $37^{\circ} \mathrm{C}$ and exposed for $15 \mathrm{~min}$ at room temperature. Negative controls (no DNAs) were incubated in each experiment and samples run concurrently with control samples.

Immunohistochemistry for detection of IL-7 and IL-7 receptor proteins. Frozen sections of normal human intestinal mucosa were fixed with $2 \%$ periodate lysine paraformaldehyde. After blocking nonspecific binding sites, $6-\mu \mathrm{m}$ sections were incubated with purified rabbit antihuman IL-7 IgG antibody (polyclonal, $10 \mu \mathrm{g} / \mathrm{ml}$; Collaborative Research Inc., Lexington, MA) or purified rabbit IgG ( $10 \mu \mathrm{g} / \mathrm{ml}$, negative control). Sections were also stained with anti-human IL-7 receptor mAb (clone M29, IgG2b; Genzyme Corp., Cambridge, MA) or isotypematched control antibody (clone 49.2 IgG2b; PharMingen, San Diego, $\mathrm{CA}$ ). The sections were then reacted with biotinylated goat anti-rabbit IgG and goat anti-mouse IgG, respectively, and incubated with StreptoAvidin-enzyme conjugates (Vectastain $\mathrm{ABC}$ kit; Vector Laboratories Inc., Burlingame, CA). The localization of IL-7 or IL-7 receptor was visualized by the incubation with diaminobenzidine solution and counterstained with methylgreen.

In situ hybridization for detection of IL-7 and IL-7 receptor mRNA. 6- $\mu \mathrm{m}$ cryosections of normal human intestinal mucosa were fixed with 4\% paraformaldehyde and investigated using digoxigenin-labeled probes and the in situ hybridization kit (Oncor Inc., Gaithersburg, MD) as previously described (16). IL-7 mRNA was detected with an antisense oligonucleotide of 30 bases in length; 5' AGTGCAGTTCAACAGTATTGTTGTGCCTTC $3^{\prime}$. As a negative control probe we used synthetic sense strand IL-7 probe 30-mer oligonucleotide; 5' GAAGGCACAACAATACTGTTGAACTGCACT 3'. IL-7 receptor mRNA was detected with an antisense oligonucleotide of 40 bases in length; 5' GGTTCAATGTCAGGATTCCAGATTGGAGAGAAAATGGAGG $3^{\prime}$. As a negative control probe we used the synthetic sense strand IL-7 receptor probe 40-mer oligonucleotide; 5' CCTCCATTTTCTCTCCAATCTGGAATCCTGACATTGAACC 3 '. Bound digoxigenin-labeled probes were visualized using an antidigoxigenin antibody (Boehringer Mannheim Biochemicals) conjugated to alkaline phosphatase and 5-bromo-chloro-3-indoylphosphate as a substrate.

Preparation of mucosal lymphocytes from the intestinal mucosa. IELs and LPLs were isolated from surgically resected intestinal specimens using enzymatic techniques as previously described (22). Briefly, the dissected mucosa was incubated with $\mathrm{Ca}^{++} \mathrm{Mg}^{++}$-free Hanks' buffered saline solution containing $1 \mathrm{mM}$ dithiothreitol (Sigma Chemical Co., St. Louis, MO) to remove mucus. The mucosa then incubated four times in medium containing $0.75 \mathrm{mM}$ EDTA (Sigma Chemical Co.). The supernatants from these incubations containing IEL population and LPLs were collected and incubated in medium with $0.02 \%$ collagenase (Worthington Biochemical Corp., Freehold, NJ) and $0.01 \%$ DNase (Worthington Biochemical Corp.). The fraction was pelleted twice through a $40 \%$ isotonic Percoll solution and the cells were centrifuged over Ficoll-Hypaque density gradient. The purity of resulting IELs and LPLs was analyzed by flow cytometry. Cell preparations were adequately pure, since $\alpha / \beta$ T cells made up $82-96 \%$ of the $\mathrm{CD}^{+}$cells in LPL and $72-92 \%$ in IELs, the fraction of HML-1 ${ }^{+}$(directed to a molecule expressed on many epithelial lymphocytes including $90 \%$ of human IELs, kindly provided by M. Brenner, Dana-Farber Cancer Institute, Boston, MA) cells was $>90 \%$ in all IELs, and the CD4/CD8 ratio was $<0.1$ in IELs and $>2.2$ in LPLs. They were used for further experiments immediately or after culture in medium (RPMI 1640 supplemented with $10 \%$ FCS, penicillin-streptomycin-fungizone, gentamycin, Hepes buffer).

Paired PBLs were also isolated by Ficoll-Hypaque density gradient. Flow cytometry. mAbs used included anti-CD3, anti-CD4, and antiCD8 $\alpha$ (Leu-4, Leu-3a, and Leu-2a, respectively; Becton Dickinson and Co., Mountain View, CA). Anti-T cell receptor (TcR) $\alpha / \beta$ (Identi-T Pan-TcR $\alpha \beta$ ) and anti- $\delta$ chain of TcR $\gamma / \delta$ (Identi-T $\delta$ TCS 1 and Diversi$\mathrm{T} \delta \mathrm{V} 2[\mathrm{a}]$ ) were obtained from T Cell Sciences, Inc. (Cambridge, MA). Purified rabbit anti-human IL-7 IgG antibody and anti-human IL-7 receptor mAb (clone M29) were also used. Flow cytometric two-color 


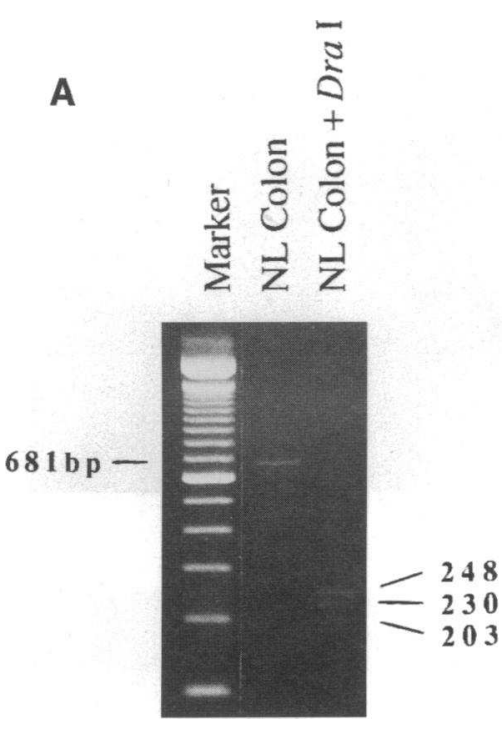

Figure 1. (A) DraI digestion of the amplified IL-7 PCR product from normal human colonic mucosa ( $\mathrm{NL} \mathrm{Co-}$ lon) demonstrated that 681 bp PCR product was digested into the predicted three fragments with 248, 230, and 203 bp (NL Colon + DraI). Marker represented 100-bp DNA ladder. (B) Southern blot hybridization demonstrated the expression of IL-7 mRNA in the normal human intestinal mucosa. IL-7 mRNA expression was detected in the colon, but was only barely detectable at other sites in the gastrointestinal tract. Note that IL7 mRNA was not readily detectable in normal human thymus tissues as reported (15), in contrast to the constitutive G3PDH mRNA was. PCR products were blotted onto nylon membrane and hybridized with IL-7 gene-specific cDNA oligonucleotide probe labeled with digoxigenin. The specificity of the amplified bands for IL-7 was validated by their predicted size ( $681 \mathrm{bp})$. Markers represented 100-bp DNA ladder. SK-HEP-1, the cell line that was used to clone the cDNA for the human IL-7, served as a positive control. For internal standard, amplified bands for G3PDH were used as the house-keeping gene. analysis carried out as described (23) using the FACScan ${ }^{\circledR}$ (Becton Dickinson and Co.). The data are presented as percentages of positive cells normalized to the number of total $\mathrm{T}\left(\mathrm{CD}^{+}\right)$cells and relative mean fluorescence. Background fluorescence was assessed by staining with control irrelevant isotype-identical mAbs.

Proliferation assays. Proliferation assays were done by culturing purified colon-derived LPLs $\left(1 \times 10^{4}\right.$ per well $)$ as well as paired PBLs $\left(1 \times 10^{5}\right.$ per well $)$ in 96-well microtiter plates for $3 \mathrm{~d}$. Mitomycintreated allogeneic PBLs $\left(1 \times 10^{4}\right.$ per well $)$ were added as a source of antigen-presenting cells. After incubation, cultures were pulsed for $4 \mathrm{~h}$ with [ ${ }^{3} \mathrm{H}$ ] thymidine $(1 \mu \mathrm{Ci} /$ well) (New England Nuclear, Boston, MA). Recombinant human IL-7 (10-1,000 U/ml; Genzyme Corp.) was

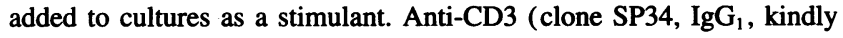
provided by N. Letvin, Beth Israel Hospital, Boston, MA) $(0.1 \mu \mathrm{g} / \mathrm{ml})$ $\mathrm{mAb}$ was used as a stimulating antigen.

Statistical analysis. Results were expressed as mean \pm SD. The statistical significance of the data was determined by the Student's $t$ test. A $P$ value of $<0.01$ was taken as significant.

\section{Results}

Normal human intestinal epithelial cells express IL-7 mRNA and produce IL-7 protein. Reverse transcription-PCR analysis demonstrated IL-7 mRNA expression in normal human colonic tissues. The specificity of amplified bands was validated by their predicted size (681 bp). To ensure the correct predicted fragments are present, we digested the amplified IL-7 PCR product by restriction enzyme DraI. As shown in Fig. $1 A, 681$ bp PCR product from normal human colonic mucosa was digested into three predicted fragments with 248,230 , and $203 \mathrm{bp}$. Southern blot analysis confirmed the expression of IL-7 mRNA in the human colonic mucosa (Fig. $1 B$ ). IL-7 mRNA expression was detected in the colon, and a detectable expression of IL7 was at other sites in the gastrointestinal tract. Equivalent hybridization was observed in Southern blot analyses using cDNA prepared from seven separate sets of tissue samples. IL-7 mRNA was not readily detectable in the normal human thymus tissues as previously reported (15).

Immunohistochemical analysis using an anti-human IL-7
mAb confirmed IL-7 expression in the human intestinal epithelial cells. As shown in Fig. $2 A$, the reactivity of the anti-human IL-7 IgG antibody, but not rabbit IgG, was confined to colonic epithelial cells and epithelial goblet cells in normal human intestinal mucosal tissues. We also used in situ hybridization, which clearly yielded IL-7 mRNA expression in the intestinal epithelial cells in the saggital, as well as cross section of colonic tissues. As shown in Fig. $2 B$, in situ hybridization demonstrated that all intestinal epithelial cells stained positively, but the strongly positive staining cells are intestinal goblet cells in the mucosa. These results suggested that $\mathrm{IL}-7$ protein is produced by human intestinal epithelial cells and may be accumulated in the mucin glycoprotein in the goblet cells.

Normal human intestinal mucosal lymphocytes express IL7 receptor on the cell surface. Since IL-7 has previously been shown to stimulate the growth of $\mathrm{T}$ cell progenitors in mouse thymus and fetal liver (9), we sought to determine whether locally produced IL-7 in the intestinal mucosa affects mucosal lymphocytes. We first studied IL-7 receptor expression in IELs and LPLs. Immunohistochemical analysis demonstrated that both LPLs and IELs in the normal human colonic mucosa express the receptor for IL-7 (Fig. $3 A$ ). We also used in situ hybridization, which yielded IL-7 receptor mRNA expression in the intestinal mucosal lymphocytes in normal colonic mucosa (Fig. $3 B$ ).

We then isolated mucosal lymphocytes from human colonic tissue, and studied the expression of IL-7 receptor mRNA and cell surface expression of $\mathrm{IL-7}$ receptor. As shown in Fig. 4, PCR and Southern blot analysis demonstrated IL-7 receptor mRNA in the LPLs of normal intestinal mucosa. The specificity of amplified bands was validated by their predicted size ( 362 bp). Interestingly, human colonic epithelial cell lines, Caco-2, also expressed IL-7 receptor mRNA. However, the human colonic epithelial cell line, HT29-18-N2, expressed no detectable expression of IL-7 receptor. The cell surface expression of IL7 receptor by mucosal lymphocytes was confirmed by using flow cytometric analysis of freshly isolated LPLs (Fig. 5). On 

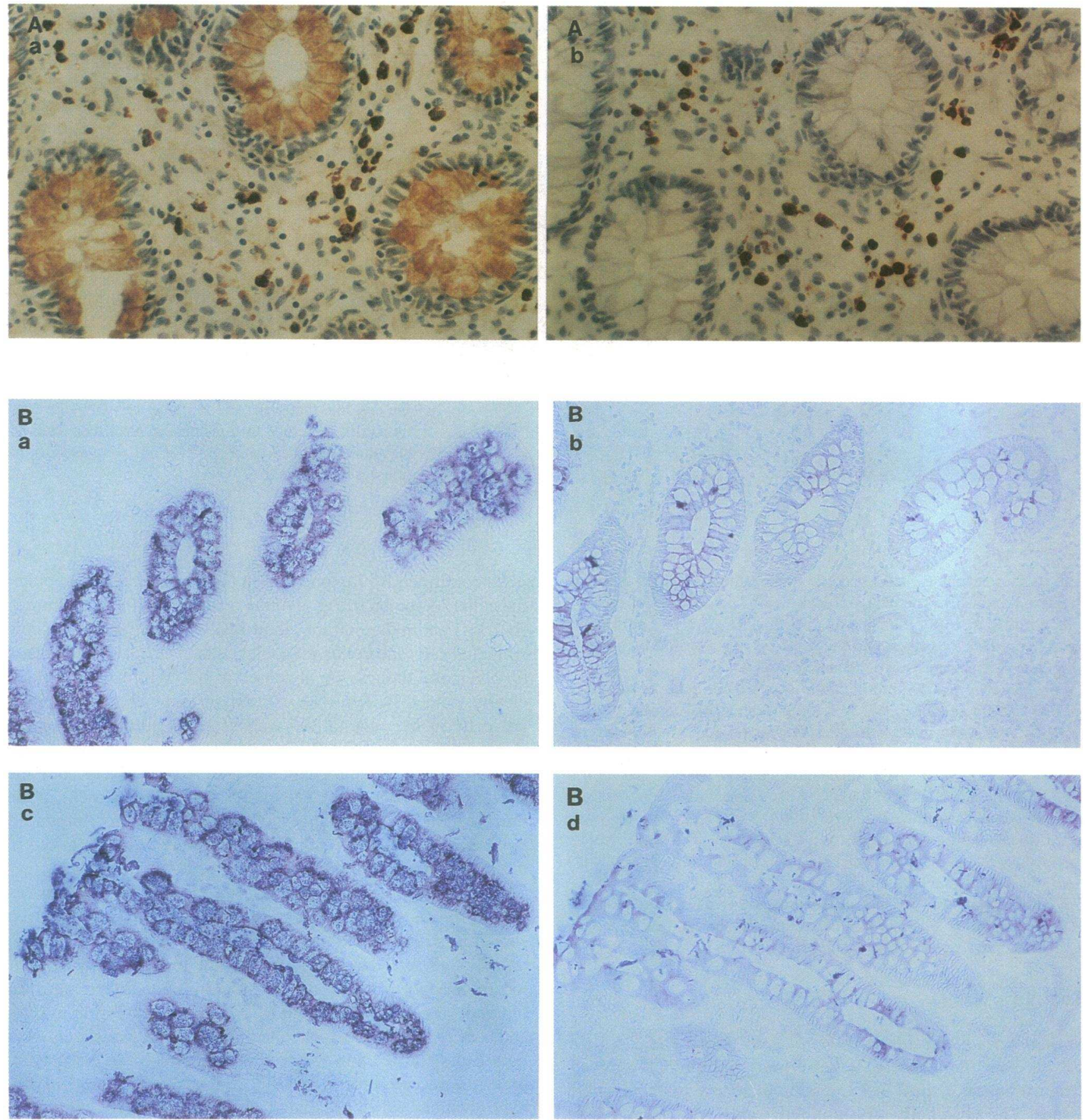

Figure 2. (A) Immunohistochemical analysis using rabbit anti-human IL-7 antibody confirmed IL-7 protein expression in the human intestinal epithelial cells and epithelial goblet cells. The reactivity of anti-human IL-7 IgG antibody $(10 \mu \mathrm{g} / \mathrm{ml})(a)$, but not control rabbit IgG (10 $\mu \mathrm{g} / \mathrm{ml})$ $(b)$ is confined to the colonic epithelial cells in the normal human intestinal mucosal tissues. Note that biotin-conjugated goat anti-rabbit antibody alone did not show the reactivity. $(B)$ In situ hybridization demonstrated the expression and localization of IL-7 mRNA in human intestinal epithelial cells. Phase contrast micrograph of serial cross section ( $a$ and $b$ ) and saggital section ( $c$ and $d$ ) of a human colonic mucosa after colorimetric detection of hybridized digoxigenin-labeled human IL-7 oligonucleotide antisense ( $a$ and $c$ ) and sense (as a negative control) ( $b$ and $d$ ) probes. IL-7 mRNA was expressed ( $a$ and $c$ ) in the colonic epithelial cells and epithelial goblet cells in the intestinal mucosa.

the contrary, IL-7 receptor was not found in freshly isolated PBLs obtained from the same individuals (Fig. 5), though those PBLs were shown to express IL-7 mRNA by Southern blot hybridization (Fig. 4).
IL-7 regulates the proliferation of human intestinal mucosal lymphocytes. Subsequently, functional activity of IL-7 receptor was assessed by the utility of exogenous recombinant IL-7 (rIL7) to stimulate the growth of freshly isolated intestinal mucosal 

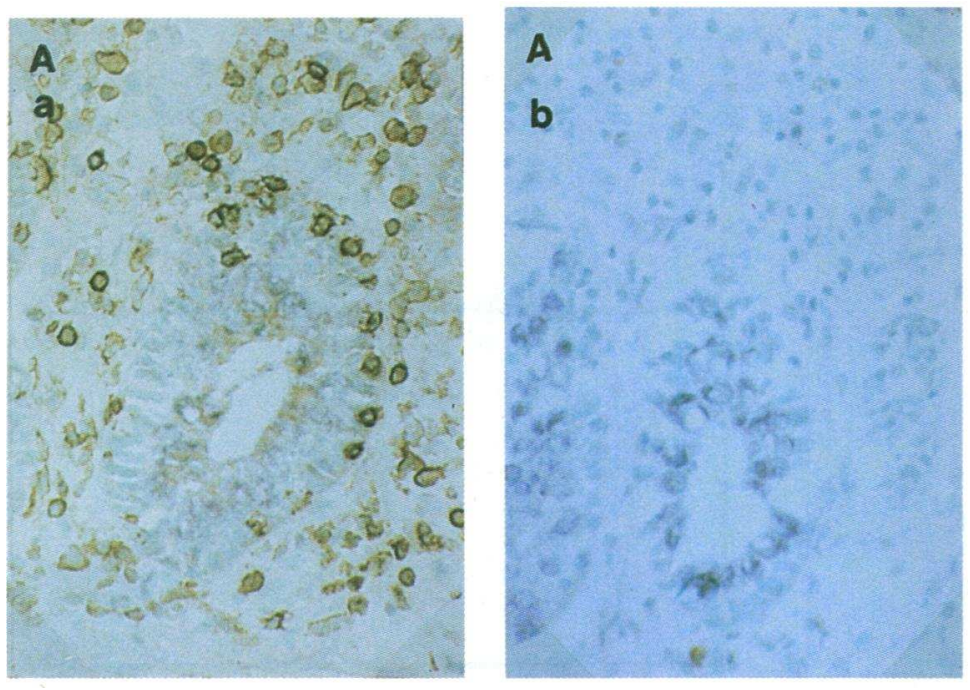

Figure 3. (A) Immunohistochemical analysis demonstrated that LPLs as well as IELs in the normal human colonic mucosa expressed the receptor for IL-7. The reactivity of anti-human IL-7 receptor mAb (clone $\mathrm{M} 29 ; 10 \mu \mathrm{g} / \mathrm{ml}$ ) $(a)$, but not control isotype-matched $\mathrm{mAb}$ (clone $49.2 ; 10 \mu \mathrm{g} / \mathrm{ml}$ ) $(b)$ is confined to the LPLs and IELs. Note that biotin-conjugated goat antimouse antibody alone did not show specific reactivity. $(B)$ In situ hybridization demonstrated the expression and localization of IL-7 receptor mRNA in the human intestinal mucosal lymphocytes. Phase contrast micrograph of sections of a human colonic mucosa after colorimetric detection of hybridized digoxigenin-labeled human IL-7 receptor oligonucleotide antisense $(a)$ and sense (as a negative control) $(b)$ probes. IL-7 receptor mRNA was expressed $(a)$ in the colonic mucosal lymphocytes in the intestinal mucosa.

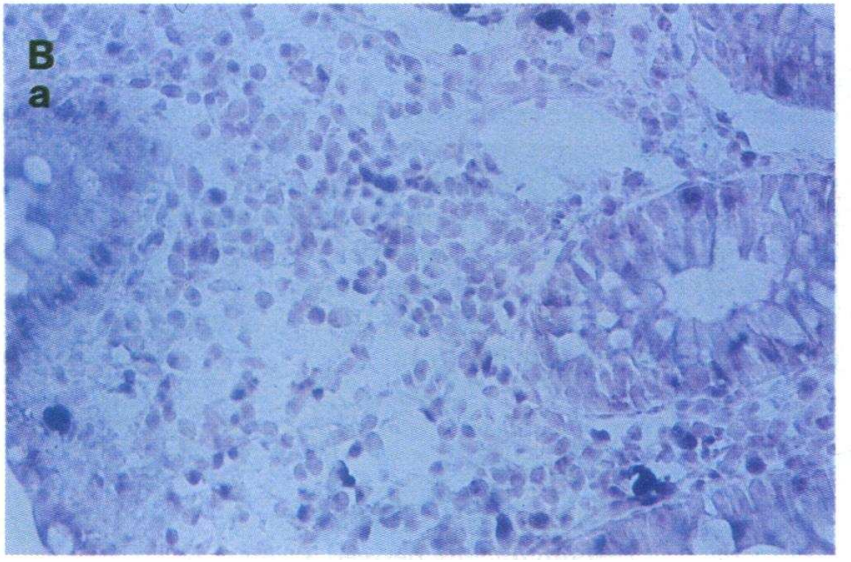

lymphocytes. rIL-7 alone stimulated a significant increase in DNA synthesis in freshly isolated LPLs from seven different individuals (Fig. $6 A[a]$ ). A determination of cell yield in LPL cultures verified that the addition of rIL-7 alone caused an increase in cell recovery (Fig. $6 A[c]$ ). However, rIL-7 inhibited anti-CD3 mAb-induced DNA synthesis and proliferative responses of LPLs in a dose-dependent fashion (Fig. $6 A[b]$ ). The number of cells in LPL cultures after stimulation with rIL7 and anti-CD3 mAb was significantly decreased, compared to cultures established with anti-CD3 $\mathrm{mAb}$ alone (Fig. $6 A[c]$ ). These results contrasted with the proliferative responses of freshly isolated PBLs obtained from the same individual. Freshly isolated PBLs from the same patients obtained at the time of endoscopy showed no significant increase in DNA synthesis or cell yield after stimulation with rIL-7 alone (Fig. $6 B$, [ $a$ and $c$ ]). However, the DNA synthesis and the number of PBL in culture after stimulation with rIL-7 and anti-CD3 mAb significantly increased (Fig. $6 B,[b$ and $c]$ ). Since previous studies have also shown that IL-7 is not directly mitogenic on peripheral blood $\mathrm{T}$ cells in short time culture (14), our results suggest that IL-7 acts quite differently on mucosal and peripheral lymphocytes.

Finally, the surface expression of lymphocyte-associated molecules was assessed on rIL-7-stimulated LPLs in the nor-

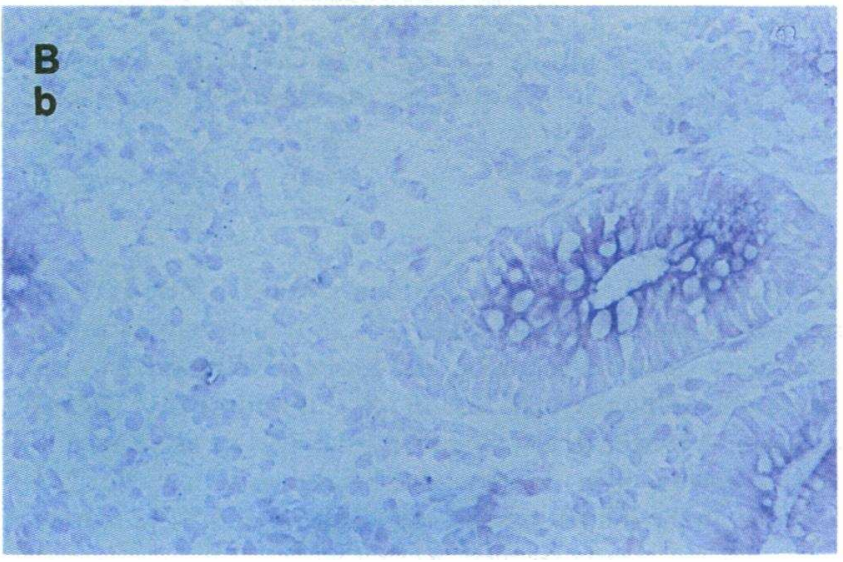

mal human intestinal mucosa by flow cytometry. These cells were $95 \% \mathrm{TcR} \alpha / \beta^{+}, 5 \% \mathrm{TcR} \gamma / \delta^{+}, 60 \% \mathrm{CD} 8 \alpha^{+}$, and $40 \%$ $\mathrm{CD} 4$, no different from the phenotype of freshly isolated normal LPLs as reported. Interestingly, cell surface expression of CD3 in LPLs stimulated with anti-CD3 mAb + rIL-7 was significantly decreased compared with that in LPLs stimulated with anti-CD3 mAb alone (Fig. $7 \mathrm{a}$ ). Relative mean fluorescence of CD3 expression in anti-CD3 mAb + IL-7 stimulated LPLs was decreased from $145 \pm 17$ (that in anti-CD3 mAb-stimulated LPLs) to $81 \pm 6$, though that of $\operatorname{TcR} \alpha / \beta$ expression was unchanged. This result also contrasted with the case of freshly isolated PBLs where mean fluorescence of $\mathrm{CD} 3$ expression was rather increased in anti-CD3 $\mathrm{mAb}+\mathrm{IL}-7$ stimulated PBLs (170 \pm 8 ) compared with that in anti-CD3 mAb-stimulated PBLs $(162 \pm 3)$. This result is comparable to the findings that rIL-7 inhibited anti-CD3 mAb-induced DNA synthesis and proliferative responses of freshly isolated LPLs, but not PBLs.

\section{Discussion}

IL-7 was originally described as a growth factor for precursor B cells (9-11). Subsequent in vitro studies have demonstrated that IL-7 is also a potent costimulus for both murine and human, immature and mature cells of the T cell lineage (12-15). More- 

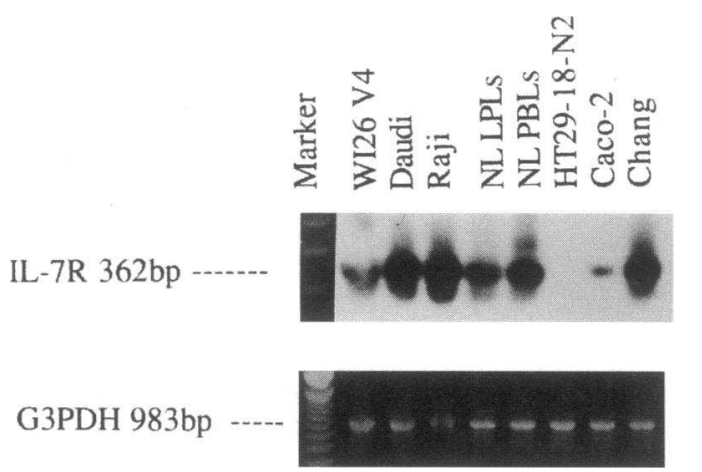

Figure 4. Southern blot hybridization demonstrated the IL-7 receptor mRNA expression in freshly isolated LPLs from human intestinal mucosa. The specificity of the amplified bands for IL-7 receptor mRNA was validated by their predicted size $(362 b p)$. Markers represented 100-bp DNA ladder. WI26 V4, the cell line that was used to clone the cDNA for the human IL-7 receptor, served as a positive control. Human B cell lymphoma cell lines Daudi and Raji, and human hepatocyte cell line Chang expressed IL-7 receptor mRNA. Interestingly, human colonic epithelial cell lines, Caco-2, also expressed IL-7 receptor mRNA. However, human colonic epithelial cell line HT29-18-N2 expressed no detectable expression of IL-7 receptor. For internal standard, amplified bands for G3PDH were used.

over, IL-7 enhances the generation of cytotoxic T cells (24), lymphokine-activated killer cells $(24,25)$, and induces proinflammatory cytokine secretion and tumoricidal activity of peripheral blood monocytes (26). In mice, abundant IL-7 mRNA expression has been demonstrated in bone marrow stromal cells, thymus, spleen, liver, kidney, and keratinocytes $(9,16,27)$. However, in the human tissues, the localization of IL-7 expression is not yet clearly defined. Recent studies have shown that IL-7 is expressed in human thymus, spleen, and keratinocytes $(15,16)$, though a potential role of IL-7 in peripheral lymphoid tissues remains unclear. In the present study we demonstrated the presence of IL-7 mRNA and IL-7 protein expression in human intestinal epithelium. Immunohistochemical and in situ hybridization analysis of intestinal mucosa have demonstrated that the epithelial goblet cells are the likely major source of IL7 in their tissues.

Recent studies have demonstrated that interactions between mucosal lymphocytes and intestinal epithelial cells are crucial for maintaining mucosal immunity. In fact, CD1d expressed on intestinal epithelial cells was shown to be an important ligand for $\mathrm{CD}^{+}$mucosal $\mathrm{T}$ cell-epithelial cell interactions (4). It has been also reported that cytokines released from mucosal mononuclear cells affect intestinal epithelial cell differentiation $(7,8)$. However, the signals from the epithelium to mucosal lymphocytes remain to be defined. In this study we provide evidence that IL-7 may regulate the proliferation and functional differentiation of mucosal lymphocytes. It has been shown that IL-7 induces an increase in $\mathrm{TcR} \alpha / \beta^{+} \mathrm{CD} 4^{-} \mathrm{CD} 8^{-} \mathrm{T}$ cells in the lymph node and spleen of athymic nude mice (28). IL-7 has also been shown to be an essential cofactor for V(D)J rearrangement of the $\operatorname{TcR} \beta$ gene in precursor $T$ cells (29). Moreover, recent evidence of an extrathymic pool of TcR $\alpha / \beta^{+}$ mucosal lymphocytes in the gut suggests that intestinal epithelial cells may share some differentiation-inducing capacities

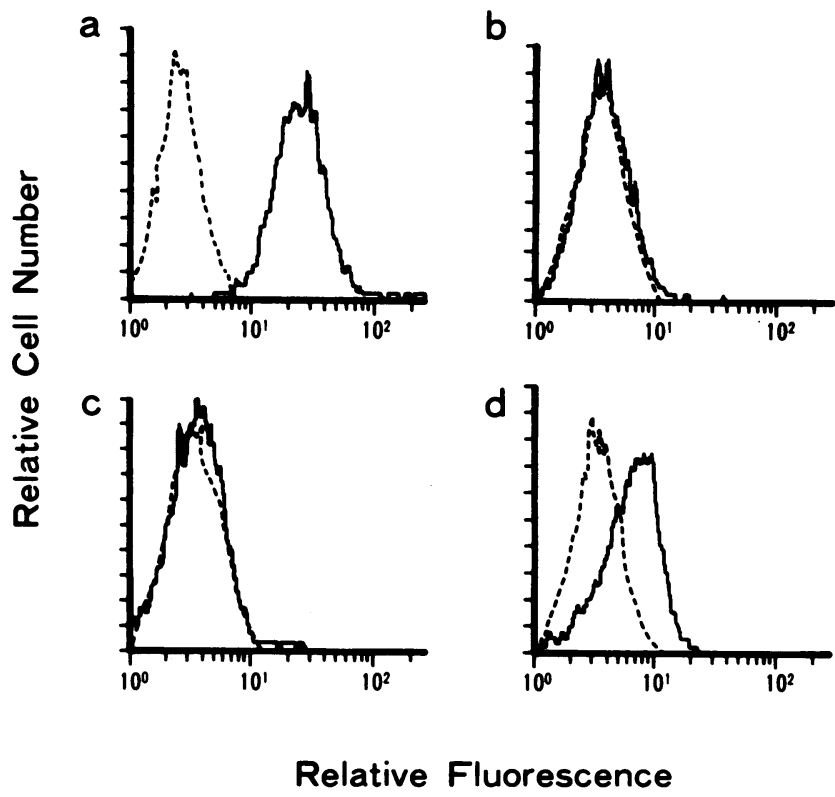

Figure 5. Flow cytometric analysis of cell surface IL-7 receptor. FACS demonstrates cell surface expression of IL-7 receptor in freshly isolated intestinal mucosal lymphocytes, but not in freshly isolated PBLs. Daudi (a) (as a positive control), Raji (b) (as a negative control), freshly isolated normal human PBLs $(c)$, and freshly isolated normal human LPLs from intestinal mucosa $(d)$ were stained with anti-IL-7 receptor mAb (M29) (-) or isotype-matched control mAb (- - -), and FITC-conjugated goat anti-mouse IgG F $\left(\mathrm{ab}^{\prime}\right)_{2}$. A minimum of 5,000 cells was analyzed for each histogram.

with thymic epithelial cells, leading to in situ TcR rearrangement of extrathymically derived $T$ cells (30). In concert with our results that the intestinal epithelium produces IL-7, these results suggest that $\mathrm{IL}-7$ may serve as a regulatory factor for the differentiation of intestinal mucosal lymphocytes.

How does locally produced IL-7 regulate mucosal lymphocytes? Localization of the IL-7 receptor, like that of IL-7 itself, has not been well defined in human tissues. In this study, immunohistochemical analysis and Southern blot hybridization demonstrated that LPLs in the normal human colonic mucosa expressed the receptor for IL-7. The cell surface expression of IL7 receptor by mucosal lymphocytes was confirmed by using flow cytometric analysis of freshly isolated LPLs. In contrast, IL-7 receptor was not found on the cell surface of freshly isolated PBLs, though those PBLs were shown to express IL-7 mRNA by Southern blot hybridization. Previous studies have shown that IL-7 stimulates the proliferation of human mature $\mathrm{T}$ cells only after exogenous stimulation in short-term culture $(13,14)$. Our result, in concert with these findings, suggests that IL-7 receptor protein on the cell surface are not expressed by resting PBLs, but expressed by those PBLs after activation. Therefore, our results indicate that mucosal lymphocytes may be activated with continuous stimulation by a number of microbial or self antigens, and express IL-7 receptor. We have also demonstrated that rIL-7 alone stimulates a significant increase in DNA synthesis, and causes an eventual increase in cell recovery of isolated mucosal lymphocytes. Unexpectedly, rIL-7 inhibited anti-CD3 mAb-induced DNA synthesis and proliferative 

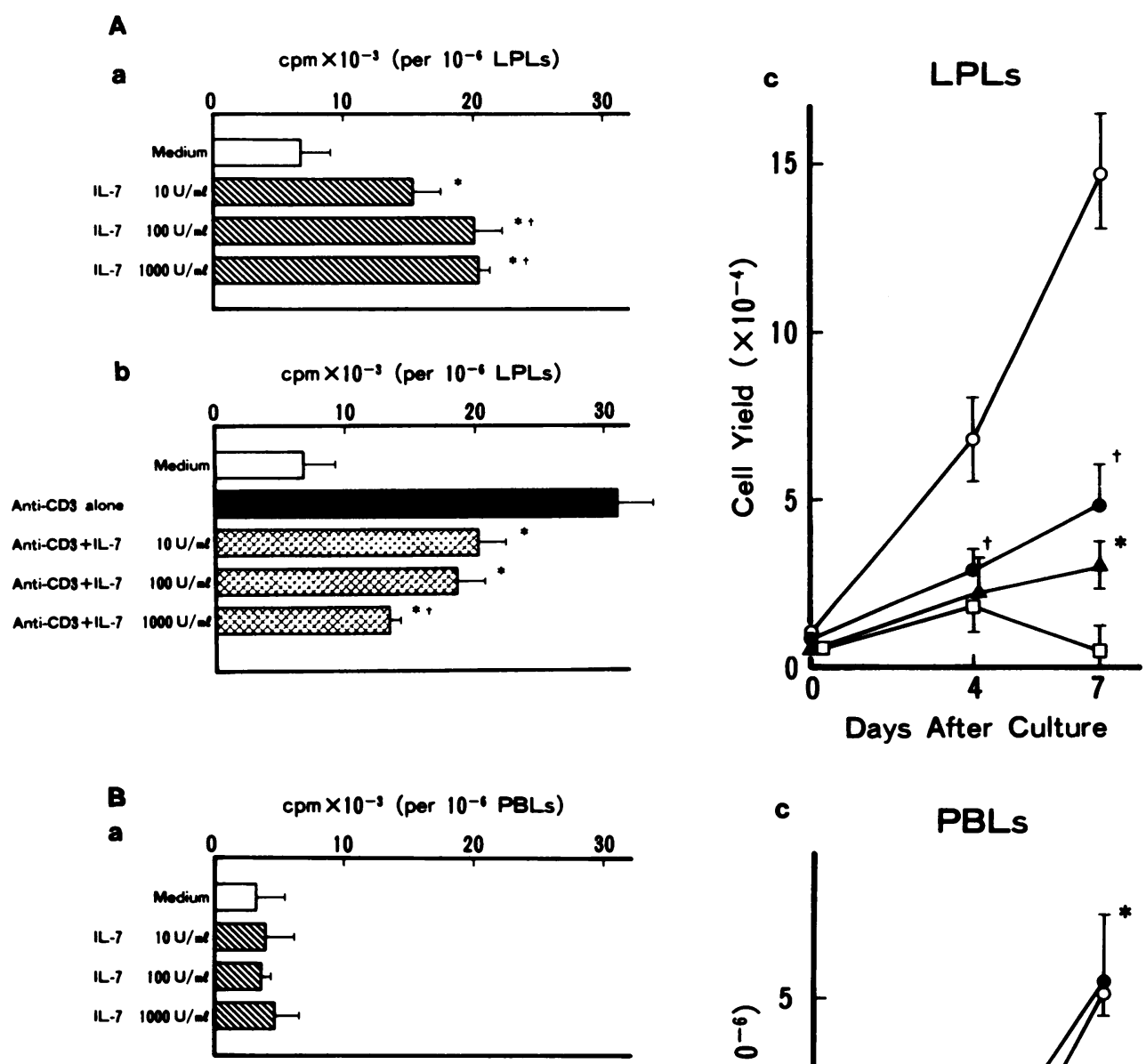

b

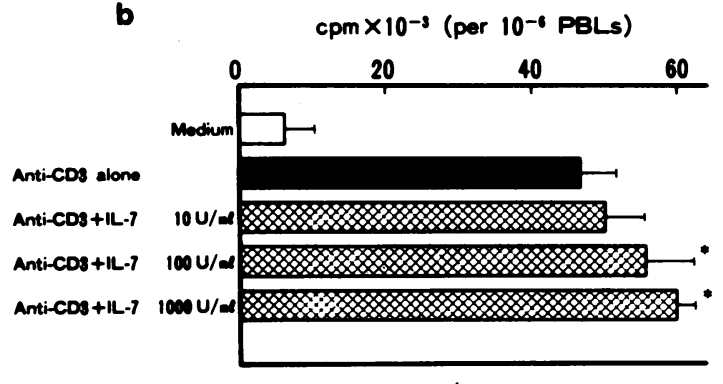

Figure 6. (A) The effect of human IL-7 in isolated mucosal lymphocytes from the human intestinal tissues. (a) rIL-7 alone stimulated significant increase in DNA synthesis in freshly isolated LPLs ( $* P<0.01$ different from control; ${ }^{\dagger} P<0.01$ different from IL$710 \mathrm{U} / \mathrm{ml}$ ), But (b) rIL-7 inhibited anti-CD3 mAb-induced DNA synthesis in a dose-dependent fashion ${ }^{*} P<0.01$ different from anti-CD3 alone; ${ }^{\dagger} P<0.01$ different from anti-CD3 + IL-7 $100 \mathrm{U} /$ $\mathrm{ml}$ ). (c) Determination of cell yield in LPL culture verified that rIL-7 caused an significant increase in cell recovery after 7-d culture ( $\Delta-\Delta)$, compared to culture with rIL-2 alone $(\square-\square)(* P$ $<0.01$ ). The number of cells in LPL culture was increased after stimulation with anti-CD3 $\mathrm{mAb}$ alone (O-O), but rIL-7 conversely decreased this anti-CD3 mAbinduced proliferation of LPLs $(\bullet-\bullet)\left({ }^{*} P<0.01\right.$, different from anti-CD3 mAb alone). $(B)$ The effect of human IL-7 in freshly isolated PBLs. (a) Freshly isolated PBLs from the same patients obtained at the time of endoscopy showed no significant increase in DNA synthesis after stimulation with rIL-7 alone. However, $(b)$ rIL-7 augmented anti-CD3 mAb-induced proliferation of PBLs, compared to that in the culture with antiCD3 mAb alone ( $* P<0.01)$. (c) Determination of cell yield in PBL culture verified that rIL-7 caused no significant increase in cell recovery ( $\Delta-\Delta)$, compared to culture with rIL-2 alone ( $\square-\square)$. The number of PBL in culture after stimulation with rIL-7 and anti-CD3 mAb was not significantly increased $(\bullet-\bullet)$, compared to culture with antiCD3 mAb alone (O-O). responses of LPLs in a dose-dependent fashion. The number of cells in LPL cultures after stimulation with rIL-7 and anti-CD3 $\mathrm{mAb}$ were significantly decreased, compared with those in the culture with rIL-2 alone, rIL-7 alone, or rIL-7 and mitogens. These results differed significantly from those seen in proliferative responses of PBLs. IL-7 acted synergistically with antiCD3 stimulation for the induction of the proliferation of human mature $\mathrm{T}$ cells and tumor-infiltrating lymphocytes from renal cell carcinoma (31). These results also suggest that $\mathrm{IL}-7$ may stimulate mucosal lymphocytes in a different fashion from
PBLs. It is possible that IL-7 may inhibit the proliferation of mucosal cells after certain stimulation.

The importance of IL-7 as a mediator of local inflammatory responses remains unclear. Recent evidence suggests that IL-7 up-regulates the expression of macrophage-derived cytokines such as IL-8, TNF, IL-1, and IL-6 and may function as an important proinflammatory cytokine (32). A possible role for IL-7 in mucosal inflammation has been suggested recently by the finding of altered IL-7 mRNA expression in the colonic epithelium in inflamed mucosa of patients with ulcerative colitis 


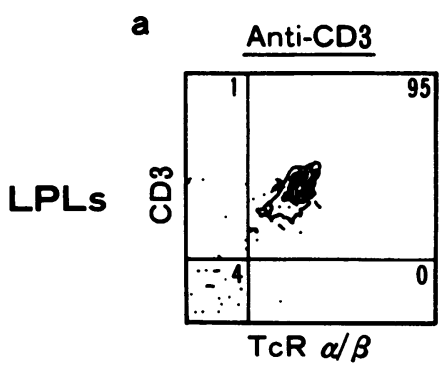

b
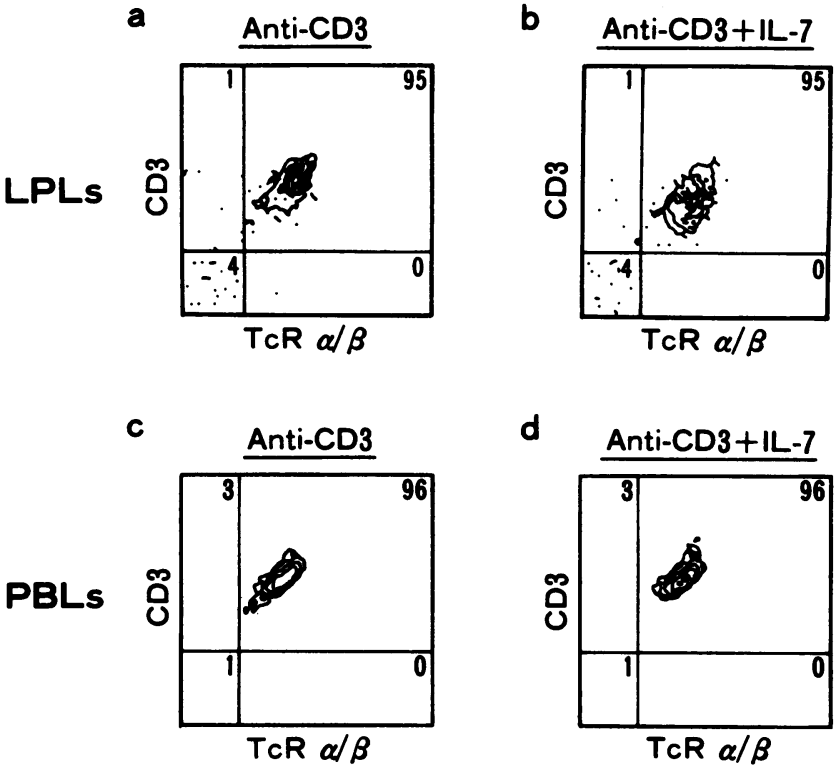

Figure 7. Flow cytometric two-color analysis for the cell surface expression of CD3 in IL-7-stimulated LPLs. Freshly isolated LPLs from normal human intestinal mucosa were analyzed by flow cytometry and were $95 \% \mathrm{TcR} \alpha / \beta^{+}, 5 \% \mathrm{TcR} \gamma / \delta^{+}, 60 \% \mathrm{CD} 8 \alpha^{+}$, and $40 \% \mathrm{CD} 4$. Cell surface expression of CD3 in LPLs stimulated with anti-CD3 mAb + rIL-7 $(b)$ was significantly $(P<0.01)$ decreased compared with LPLs stimulated with anti-CD3 $\mathrm{mAb}$ alone $(a)$. Relative mean fluorescence of CD3 expression in anti-CD3 mAb + IL-7 stimulated LPLs was decreased from $145 \pm 17$ (that in anti-CD3 mAb-stimulated LPLs) to $81 \pm 6$, though that of TcR $\alpha / \beta$ expression was unchanged. This result also contrasted with that observed with freshly isolated PBLs where mean fluorescence of CD3 expression was increased in anti-CD3 $\mathrm{mAb}$ + IL-7 stimulated PBLs (170 \pm 8$)(d)$ compared with anti-CD3 mAbstimulated PBLs (162 \pm 3$)(c)$.

(Watanabe, M., unpublished data). Interestingly, IL-7 receptor expression was quite marked in the mucosal lymphocytes in severely inflamed colonic mucosa from patients with ulcerative colitis. These results favor the idea that IL-7 produced by intestinal epithelial cells may be involved in mucosal inflammation.

\section{Acknowledgments}

The authors would like to express special thanks to Professors Norman Letvin, Daniel Podolsky, and Jun-ichi Hata for critical comments; Drs. Yoshiki Hiraoka, Masahide Shiozawa, Tetsu Watanabe, and Toshiyuki Yasui for helpful technical discussion; Drs. Nagamu Inoue, Hiromasa Takaishi, Manabu Ooyama, Motoyuki Ogawa, and Motomi Yamazaki for technical assistance; and Drs. Masaki Kitajima, Masahiko Watanabe, and Tsuneo Fukushima for providing the specimens.

This study was supported in part by grants-in-aid from the Japanese Ministry of Education, Culture and Science, the Japanese Ministry of Health and Welfare, and Keio University, Tokyo, Japan.

\section{References}

1. Taguchi, T., W. K. Aicher, K. Fujuhashi, M. Yamamoto, J. R. McGhee, J. A. Bluestone, and H. Kiyono. 1991. Novel function for intraepithelial lymphocytes: murine CD3+, $\gamma \delta$ TCR T cells produce IFN- $\gamma$ and IL-5. J. Immunol. 147:37363744.
2. Barrett, T. A., T. F. Gajewski, D. Danielpour, E. B. Chang, K. W. Beagley, and J. A. Bluestone. 1992. Differential function of intestinal intraepithelial lymphocyte subsets. J. Immunol. 149:1124-1130.

3. Van Kerckhove, C., G. J. Russell, K. Deusch, K. Reich, A. K. Bhan, H. DerSimonian, and M. B. Brenner. 1992. Oligoclonality of human intestinal intraepithelial T cells. J. Exp. Med. 175:57-63.

4. Balk, S. P., E. C. Ebert, R. L. Blumenthal, F. V. McDermott, K. W. Wucherpfenning, S. B. Landau, and R. S. Blumberg. 1991. Oligoclonal expansion and $\mathrm{CD} 1$ recognition by human intestinal intraepithelial lymphocytes. Science (Wash. DC). 253:1411-1415.

5. Panja, A., R. S. Blumberg, S. P. Balk, and L. Mayer. 1993. CD1d is involved in T cell-intestinal epithelial cell interactions. J. Exp. Med. 178:11151119.

6. Janeway, C. A., Jr., B. Jones, and A. Hayday. 1988. Specificity and function of $\mathrm{T}$ cells bearing $\gamma \delta$ receptors. Immunol. Today. 9:73-76.

7. Sadlack, B., H. Merz, H. Schorle, A. Schimpl, A. C. Feller, and I. Horak 1993. Ulcerative colitis-like disease in mice with a disrupted interleukin- 2 gene. Cell. 75:253-261.

8. Kuhn, R., J. Loher, D. Rennick, K. Rajewsky, and W. Muller. 1993. Interleukin-10-deficient mice develop chronic enterocolitis. Cell. 75:263-274.

9. Namen, A. E., S. Lupton, K. Hjerrild, J. Wignall, D. Y. Mochizuki, A. E. Schmierer, B. Mosley, C. J. March, D. L. Urdal, S. Gillis, D. Cosman, and R. G. Goodwin. 1988. Stimulation of B-cell progenitors by cloned murine interleukin7. Nature (Lond.). 333:571-575.

10. Goodwin, R. G., S. Lupton, A. Schmierer, K. J. Hjerrild, R. Jerzy, W. Clevenger, S. Gillis, D. Cosman, and A. E. Namen. 1989. Human interleukin 7: molecular cloning and growth factor activity on human and murine B-lineage cells. Proc. Natl. Acad. Sci. USA. 86:302-306.

11. Morrissey, P. J., R. G. Goodwin, R. P. Nordan, D. Anderson, K. H. Grabstein, D. Cosman, J. Sims, S. Lupton, B. Acres, S. G. Reed, et al. 1989. Recombinant interleukin 7, pre-B cell growth factor, has costimulatory activity on purified mature T cells. J. Exp. Med. 169:707-716.

12. Chazen, G. D., G. M. B. Pereira, G. LeGros, S. Gillis, and E. M. Shevach. 1989. Interleukin 7 is a T-cell growth factor. Proc. Natl. Acad. Sci. USA. 86:59235927.

13. Welch, P. A., A. E. Namen, R. G. Goodwin, R. Armitage, and M. D. Cooper. 1989. Human IL-7: a novel T cell growth factor. J. Immunol. 143:35623567.

14. Armitage, R. J., A. E. Namen, H. M. Sassenfeld, and K. H. Grabstein. 1990. Regulation of human T cell proliferation by IL-7. J. Immunol. 144:938941.

15. Goodwin, R. G., and A. E. Namen. 1991. Interleukin-7. In The Cytokine Handbook. A. W. Thomson, editor. Academic Press Inc., San Diego, CA. 191200.

16. Heufler, C., G. Topar, A. Grasseger, U. Stanzl, F. Koch, N. Romani, A. E. Namen, and G. Schuler. 1993. Interleukin 7 is produced by murine and human keratinocytes. J. Exp. Med. 178:1109-1114.

17. Park, L. S., D. J. Friend, A. E. Schmierer, S. K. Dower, and A. E. Namen. 1990. Murine interleukin 7 (IL-7) receptor. Characterization on an IL7-dependent cell line. J. Exp. Med. 171:1073-1089.

18. Goodwin, R. G., D. Friend, S. F. Ziegler, R. Jerzy, B. A. Falk, S. Gimpel, D. Cosman, S. K. Dower, C. J. March, A. E. Namen, and L. S. Park. 1990. Cloning of the human and murine interleukin-7 receptors: demonstration of a soluble form and homology to a new receptor superfamily. Cell. 60:941-951.

19. Benjamin, D., V. Sharma, T. J. Knoblock, R. J. Armitage, M. A. Dayton, and R. G. Goodwin. 1994. B cell IL-7. Human B cell lines constitutively secrete IL-7 and express IL-7 receptors. J. Immunol. 152:4749-4751.

20. Podolsky, D. K., K. Lynch-Devaney, J. L. Stow, P. Oates, B. Murgue, M. DeBeaumont, B. E. Sands, and Y. R. Mahida. 1993. Identification of human intestinal trefoil factor. Goblet cell-specific expression of a peptide targeted for apical secretion. J. Biol. Chem. 268:6694-6702.

21. Miyake, S., H. Yagita, T. Maruyama, H. Hashimoto, N. Miyasaka, and K. Okumura. 1993. $\beta 1$ integrin-mediated interaction with extracellular matrix proteins regulates cytokine gene expression in synovial fluid cells of rheumatoid arthritis patients. J. Exp. Med. 177:863-868.

22. Bull, D. M., and M. A. Bookman. 1977. Isolation and functional characterization of intestinal mucosal lymphoid cells. J. Clin. Invest. 59:966-974.

23. Fabbi, M., V. Groh, and J. L. Strominger. 1992. IL-7 induces proliferation of $\mathrm{CD}^{-/ \text {low }} \mathrm{CD} 4^{-} \mathrm{CD} 8^{-}$human thymocyte precursors by an IL-2 independent pathway. Int. Immunol. 4:1-5.

24. Alderson, M. R., H. M. Sassenfeld, and M. B. Widmer. 1990. Interleukin 7 enhances cytolytic $\mathrm{T}$ lymphocyte generation and induces lymphokine-activated killer cells from human peripheral blood. J. Exp. Med. 172:577-587.

25. Stotter, H., M. C. Custer, E. S. Bolton, L. Guedez, and M. T. Lotze. 1991. IL-7 induces human lymphokine-activated killer cell activity and is regulated by IL-4. J. Immunol. 146:150-155.

26. Alderson, M. R., T. W. Tough, S. F. Ziegler, and K. H. Grabstein. 1991. 
Interleukin 7 induces cytokine secretion and tumoricidal activity by human peripheral blood monocytes. J. Exp. Med. 173:923-930.

27. Wiles, M. V., P. Ruiz, and B. A. Imhof. 1992. Interleukin-7 expression during mouse thymus development. Eur. J. Immunol. 22:1037-1042.

28. Kenai, H., G. Matsuzaki, T. Nakamura, Y. Yoshikai, and K. Nomoto 1993. Thymus-derived cytokine(s) including interleukin-7 induce increase of $T$ cell receptor $\alpha / \beta^{+} \mathrm{CD} 4^{-} \mathrm{CD} 8^{-} \mathrm{T}$ cells which are extrathymically differentiated in athymic nude mice. Eur. J. Immunol. 23:1818-1825.

29. Muegge, K., M. P. Vila, and S. K. Durum. 1993. Interleukin-7: a cofactor for $\mathrm{V}(\mathrm{D}) \mathrm{J}$ rearrangement of the $\mathrm{T}$ cell receptor $\beta$ gene. Science (Wash. DC) 261:93-95.
30. Rocha, B., P. Vassali, and D. Guy-Grand. 1991. The V $\beta$ repertoire of mouse gut homodimeric $\alpha \mathrm{CD} 8{ }^{+}$intraepithelial T cell receptor $\alpha / \beta^{+}$lymphocytes reveals a major extrathymic pathway of $\mathrm{T}$ cell differentiation. J. Exp. Med. 173:483-486.

31. Sica, D., P. Rayman, J. Stanley, M. Edinger, R. R. Tubbs, E. Klein, R. Bukowski, and J. H. Finke. 1993. Interleukin 7 enhances the proliferation and effector function of tumor-infiltrating lymphocytes from renal-cell carcinoma. Int. J. Cancer. 53:941-947.

32. Standiford, T. J., R. M. Strieter, R. M. Allen, M. D. Burdick, and S. T. Kunkel. 1992. IL-7 up-regulates the expression of IL-8 from resting and stimulated human blood monocytes. J. Immunol. 149:2035-2039. 